\title{
Effect of Cryogenic Chill on Mechanical Properties of ASTM A 494 M Grade Nickel Based Alloy Metal Matrix Composites
}

\author{
Anil Kumar Basavarajaiah Kenchanahalli *, Ananthaprasad Maravanji Gangadharaiah ${ }^{b}$, \\ Gopalakrishna Keshavanarayanac \\ ${ }^{a}$ Department of Mechanical Engineering, Jain University, Bangalore, 562 112, India \\ ${ }^{b}$ School of Engineering, Dayananda Sagar University, Bangalore, 560068, India \\ ${ }^{c}$ Centre for Incubation, Innovation, Research and Consultancy, Jyothy Institute of Technology, \\ Bangalore, 560082, India
}

Received: June 20, 2016; Accepted: August 23, 2016

\begin{abstract}
An investigation in the present research was made to fabricate and evaluate the microstructure and mechanical properties of metal matrix composites developed using cryogenically cooled copper chills, consisting of ASTM A $494 \mathrm{M}$ grade nickel alloy matrix and garnet particles as the reinforcement. The particle's amount added ranges from 3 wt. \% to 12 wt. \% in steps of $3 \%$. A stir casting process was used to fabricate the composite. The matrix alloy was melted in a casting furnace at around $1350^{\circ} \mathrm{C}$, the garnet particulates preheated to $600^{\circ} \mathrm{C}$, were introduced into the molten metal alloy. When pouring melt into mould, an arrangement was made at one end of the mould by placing copper chill blocks of varying thickness brazed with MS hallow block in which liquid nitrogen was circulated simultaneously for cryogenic effect. After solidification produced composite materials thus synthesized were examined for microstructural and mechanical properties as per ASTM standards.
\end{abstract}

Keywords: Nickel alloy, Chill casting, Garnet, Cryogenic, Mechanical properties

\section{Introduction}

Nickel in elemental form or alloyed with other metals and materials has made significant contributions to our present-day society and promises to continue to supply materials for an even more demanding future. Nickel is a versatile element and can be alloyed with most metals. Nickel and nickel alloys are used for a wide variety of applications because of their ability to withstand a wide variety of severe operating conditions involving corrosive environments, high temperatures, high stresses, strength, metallurgical stability, fabricability and weldability ${ }^{1-2}$. The majority of applications require high corrosion resistance and/or heat resistance for aircraft gas turbines, automotive exhaust valves, nuclear power systems, chemical and petrochemical industries. The demand for such functional material to provide high performance has resulted in continuous attempts being made particularly in the areas of alloy design and the use of novel processing techniques to develop composite materials as serious competitors to the traditional engineering alloys 3-10. Composite is a multi-functional system that provides characteristics not obtainable from any discrete material. Compared with unreinforced metals, metal matrix composites (MMCs) offer designers many benefits as they are particularly suited for applications requiring higher specific strength, stiffness and higher operating temperature.

In particular, the particle-reinforced MMCs have been the most popular among other composite materials over the last

\footnotetext{
* e-mail: anil.dream@gmail.com
}

two decades, because they exhibit near-isotropic properties in comparison with the continuously-reinforced matrices ${ }^{11}$. The combination of properties offered by particle-reinforced nickel metal-matrix composites makes these materials attractive for applications in the marine, aerospace, and automotive industries.

It is well known, that $\mathrm{Ni}$ alloys that freeze over a wide range of temperature are difficult to feed during solidification. The dispersed porosity caused by the pasty mode of solidification can be effectively reduced by the use of cryogenic chills. Chills extract heat at a faster rate and promote directional solidification. Therefore, chills are widely used by foundry engineers for the production of sound and quality castings ${ }^{12-17}$. With the increase in the demand for quality composites, it has become essential to produce nickel alloy composites that are free from solidification defects. Nickel alloy castings are prone to unsoundness in the form of micro-shrinkage. The primary and most important factor to consider in casting is solidification shrinkage, because it contributes significantly to the problems encountered during the feeding of castings. Therefore, cryogenic chill acts as a steep temperature gradient in desired direction and in specific location. As a consequence of using chills, the solidification conditions are altered, influencing the casting properties. The ability of the cryogenic chill to extract heat from the molten metal during freezing of the casting is dependent on the size of the chill and thermo-physical properties of the chill material ${ }^{18,19}$. 


\section{Experimental details}

\subsection{Material Selection}

\subsubsection{Matrix Material}

The chemical composition of the selected "ASTM A $494 \mathrm{M}$ grade nickel base alloy" matrix material is given in the Table 1.

Table 1: Chemical composition of matrix material ASTM A 494 $\mathrm{M}$ grade nickel base alloy. (Inconel-625)

\begin{tabular}{lc}
\hline Elements & \% by wt. \\
\hline Nickel & Balance \\
Chromium & $20.0-23.0$ \\
Iron & 5.0 \\
Molybdenum & $8.0-10.0$ \\
Niobium (plus Tantalum) & $3.15-4.15$ \\
Carbon & 0.10 \\
Manganese & 0.50 \\
Silicon & 0.50 \\
Phosphorus & 0.015 \\
Sulfur & 0.015 \\
Aluminum & 0.40 \\
Titanium & 0.40 \\
Cobalt & 1.0 \\
\hline
\end{tabular}

\subsubsection{Reinforcement}

Reinforcement material selected was Garnet, a group of silicate minerals, which is one of the hardest naturally available ceramic material [20-21]. The chemical composition of the selected garnet is given in the Table 2 .

Table 2: Chemical composition of Almandine Garnet $\left(\mathrm{Fe}_{3} \mathrm{Al}_{2} \mathrm{Si}_{3} \mathrm{O}_{12}\right)$

\begin{tabular}{lc}
\hline Elements & \% by wt. \\
\hline Aluminium Oxide & 19.0 \\
Iron Oxide & 34.10 \\
Calcium Oxide & 3.0 \\
Magnesium Oxide & 4.51 \\
Titanium Oxide & 2.80 \\
Manganese Oxide & 0.58 \\
Silica & 35.90 \\
\hline
\end{tabular}

\subsection{Metal Matrix Composite Preparation}

A stir casting process was used to fabricate the nickel base matrix alloy fused with Garnet, having reinforcement particles varying from $3 \mathrm{wt}$. $\%$ to $12 \mathrm{wt}$. $\%$ in steps of $3 \mathrm{wt} \%$ for the preparation of metal matrix composites. The matrix alloy was melted in a casting furnace at around $1350^{\circ} \mathrm{C}$ shown in Figure 1. At the same time the garnet particulate was preheated in another furnace set at $600^{\circ} \mathrm{C}$ for approximately 2 hour to remove surface impurities and assist in the adsorption of

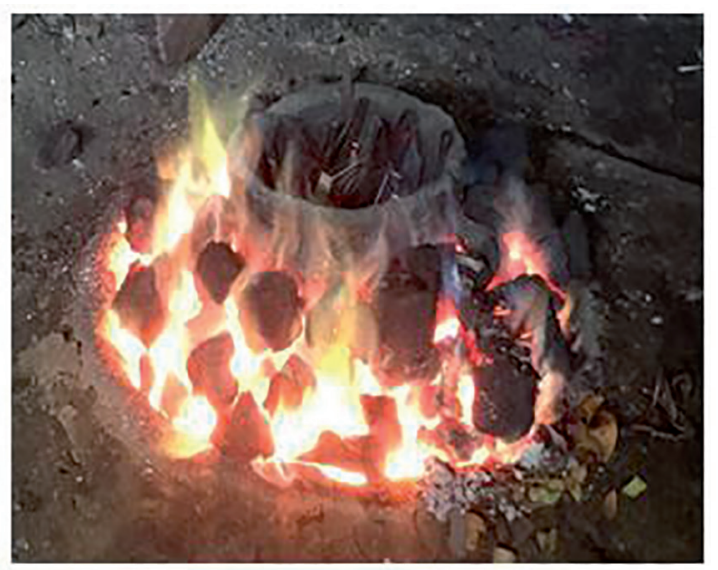

Figure 1: Casting furnace.

gases. Then the preheated 3 wt. \% of garnet particulates, were introduced evenly into the molten metal alloy. This process was repeated for 6,9 and 12 wt. \% reinforcement. Simultaneously, the molten metal was well agitated by means of a manual mixing using graphite stirrer, which was carried out for about $5 \mathrm{~min}$.

The moulds were prepared using silica sand with 5\% bentonite as binder and 5\% moisture according to American Foundry Society (AFS) standards, and were dried in an air furnace. The moulds prepared were rectangular bar shaped ingots of dimensions $150 \times 40 \times 25 \mathrm{~mm}$ as per ASTM standards. A chill block was placed adjacent to one end of the mould. The arrangement of sand moulds and chill blocks is shown in Figure 2. Also the arrangements were made in chill blocks to circulate the liquid nitrogen in and out for cryogenic effect. The chill blocks placed were made up of copper of thickness $10 \mathrm{~mm}$, brazed with hallow MS blocks of size $150 \times 35 \times 40 \mathrm{~mm}$ are shown in the Figure 3 . The molten material at $1350{ }^{\circ} \mathrm{C}$ was next poured into the sand mold. Liquid nitrogen was introduced into hallow steel block before and after pouring of the molten mixture for cryogenic effect. The above same procedure was repeated for chill thickness of 20 and $25 \mathrm{~mm}$. The same type of sand mould was also used to cast a specimen without chilling effect.

\subsection{Characterization and Tests}

Microstructural studies were carried out, using optical microscope, Nikon model Eclipse LV 150. The specimens, prepared from the produced composite for the microstructural analysis were selected from the desired location of the chill end, which are polished and etched as per ASTM E3-11 standards ${ }^{22}$.

The microstructural and chemical compositions of the samples were also analysed by Zeiss Scanning Electron Microscope (SEM) and its Energy Dispersive Spectrometer (EDS). 


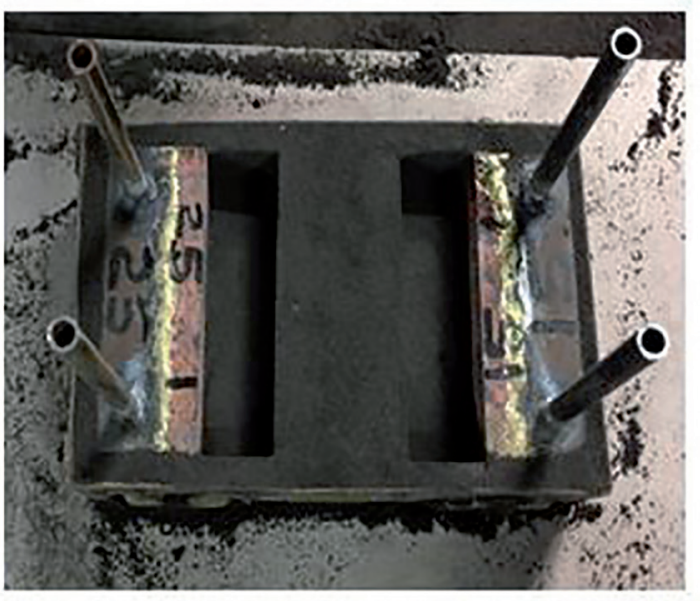

Figure 2: Sand mould with Copper end chill and arrangements for passing liquid nitrogen.

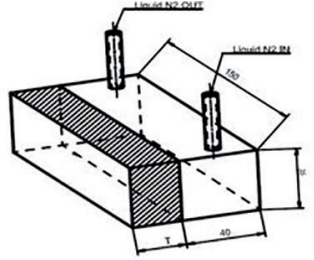

(a)

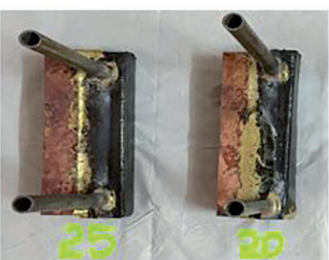

(b)
Figure 3: (a), (b) - Brazed copper chill with steel hollow block for passing liquid nitrogen.

To study the tensile behaviour and to determine the ultimate tensile strength of the matrix composites, specimens were prepared and tested as per ASTM E8 / E8M-15a [23] standard as shown in Figure 4. The specimens were machined using wire cutting. Tensile test were performed using Universal Testing Machine model: TUE-C -400 .

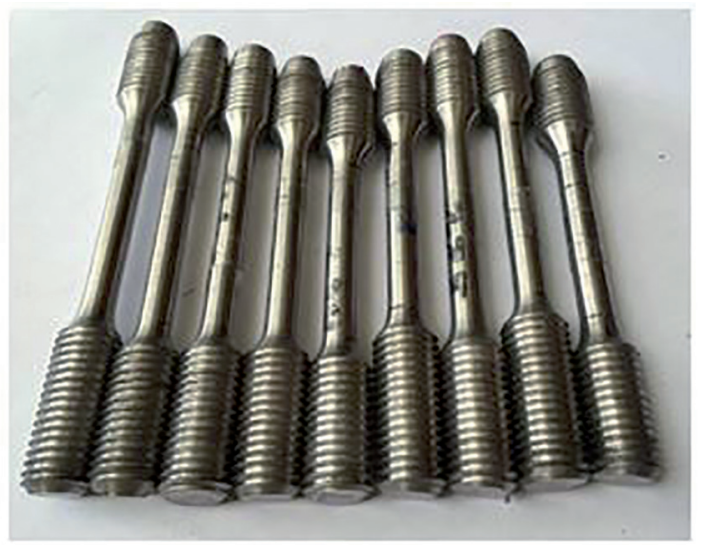

Figure 4: Tensile test specimens
The Brinell hardness testing was carried out for all polished composite specimens prepared from the developed metal matrix composite as per ASTM E10-15a [24] standard. The hardness of the specimen determined by Brinell hardness testing machine with $250 \mathrm{~kg}$ load and $5 \mathrm{~mm}$ diameter steel ball indenter. The detention time for the hardness measurement was 1 minute. The tests were carried out at three different locations taken from chill end side of the composite specimen. Each hardness result was obtained from an average of at least three repetitions on the same sample.

\section{Results and Discussions}

\subsection{Microstructural Studies}

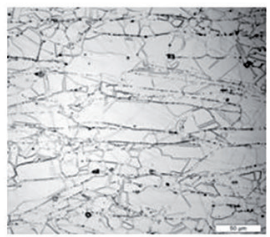

(a)
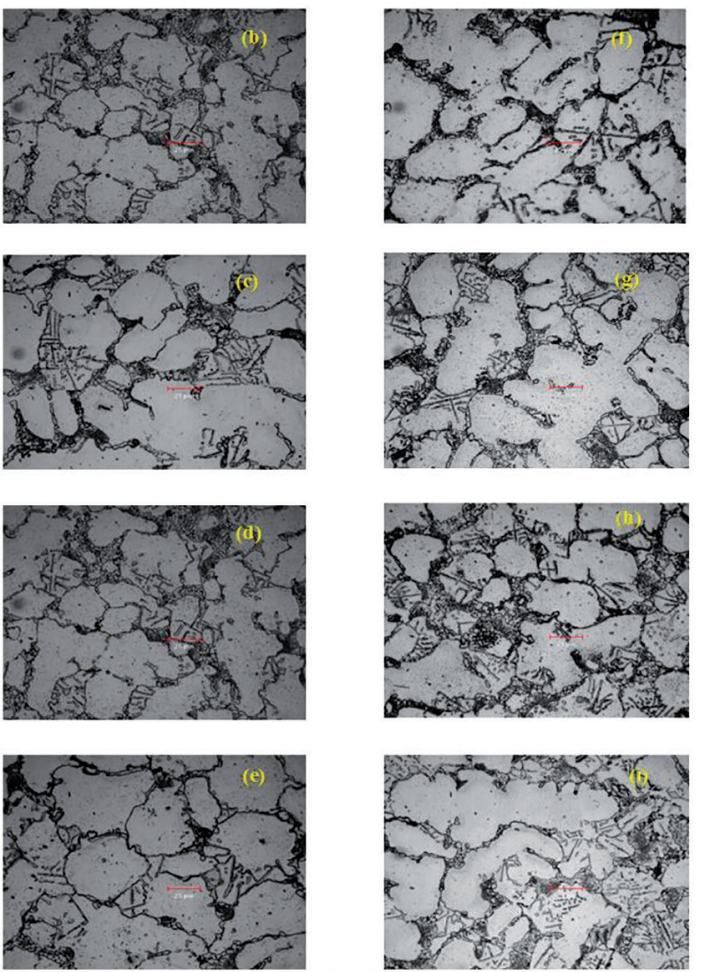

Figure 5. Microstructure images of (a) Base matrix alloy, (b) 3\% Garnet with chill, (c) 3\% Garnet with No chill, (d) 6\% Garnet with chill, (e) $6 \%$ Garnet with No chill, (f) $9 \%$ Garnet with chill, (g) $9 \%$ Garnet with No chill, (h) $12 \%$ Garnet with chill, (i) $12 \%$ Garnet with No chill. 


\subsection{SEM Analysis}
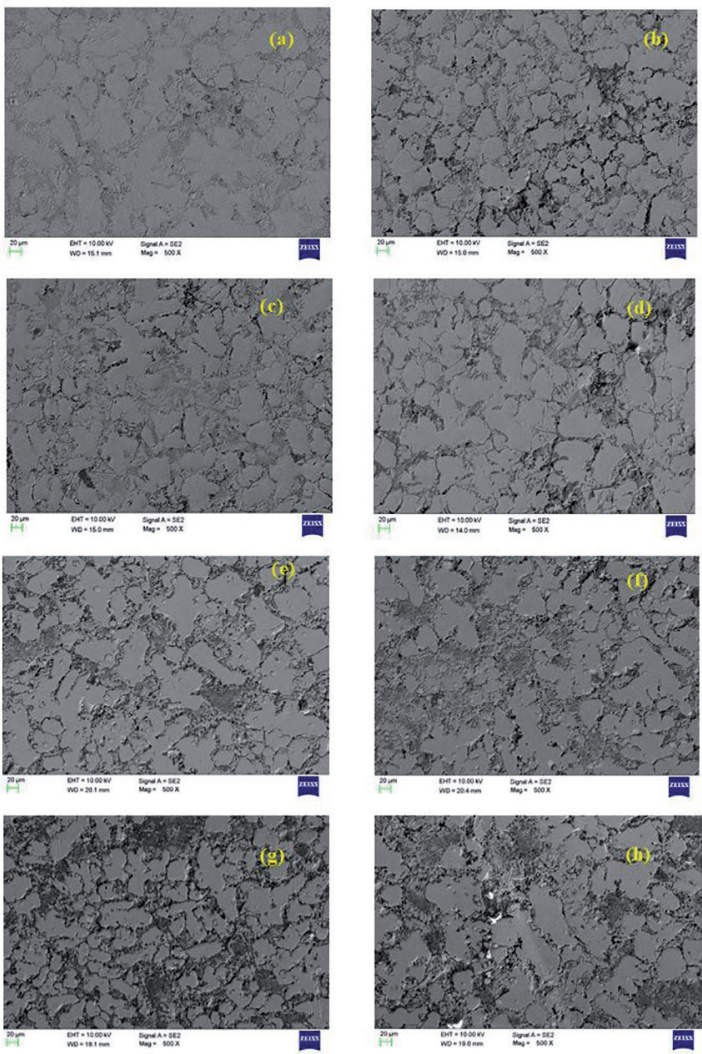

Figure 6. SEM images of (a) 3\% Garnet with chill, (b) 3\% Garnet with No chill, (c) $6 \%$ Garnet with chill, (d) $6 \%$ Garnet with No chill, (e) $9 \%$ Garnet with chill, (f) $9 \%$ Garnet with No chill, (g) $12 \%$ Garnet with chill, (h) $12 \%$ Garnet with No chill.

\subsection{Chemical Composition by EDS Test}
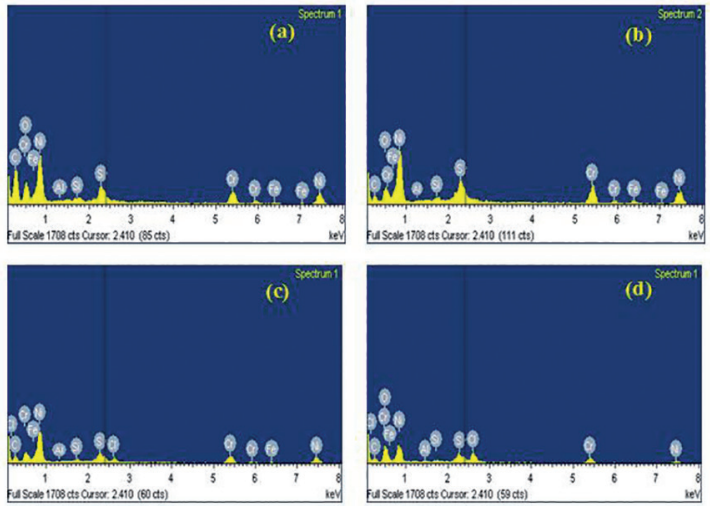

Figure 7. Chemical composition by EDS of (a) 3\% reinforcement, (b) $6 \%$ reinforcement, (c) $9 \%$ reinforcement, (d) $12 \%$ reinforcement.
Table 3: Chemical composition by EDS of (a) 3\% reinforcement, (b) $6 \%$ reinforcement, (c) $9 \%$ reinforcement, (d) $12 \%$ reinforcement.

\begin{tabular}{lcccc}
\hline Element & $\begin{array}{c}\text { Weight } \\
3 \%\end{array}$ & $\begin{array}{c}\text { Weight } \\
6 \%\end{array}$ & $\begin{array}{c}\text { Weight } \\
9 \%\end{array}$ & $\begin{array}{c}\text { Weight } \\
12 \%\end{array}$ \\
\hline C K & 2.9 & 1.27 & 2.17 & 2.5 \\
O K & 5.66 & 5.95 & 6.47 & 2.72 \\
Al K & 0.57 & 1.19 & 1.71 & 2.28 \\
Si K & 1.28 & 1.85 & 2.75 & 3.66 \\
S K & 1.91 & 2.41 & 1.53 & 1.2 \\
Cr K & 20.33 & 19.68 & 19.08 & 20.02 \\
Fe K & 5.53 & 6.63 & 7.2 & 7.9 \\
Ni K & 61.82 & 61.02 & 59.09 & 59.72 \\
Totals & 100.00 & 100.00 & 100.00 & 100.00 \\
\hline
\end{tabular}

\subsection{Tensile Strength}

Table 4. Mechanical properties of matrix material

\begin{tabular}{lcccc}
\hline $\begin{array}{l}\text { Matrix } \\
\text { material }\end{array}$ & $\begin{array}{c}\text { UTS } \\
(\mathrm{MPa})\end{array}$ & BHN & $\begin{array}{c}\text { Yield } \\
\text { Strength }\end{array}$ & $\begin{array}{c}\% \\
\text { elongation }\end{array}$ \\
\hline $\begin{array}{l}\text { ASTM A } \\
\text { 494 M }\end{array}$ & 485 & 163 & 275 & 25 \\
\hline
\end{tabular}

Table 5: UTS in N/mm ${ }^{2}$ of cryo-chilled reinforced metal matrix cast using copper chills of varying thickness.

\begin{tabular}{lcccc}
\hline $\begin{array}{l}\text { Chill } \\
\text { thickness } \\
\text { in mm }\end{array}$ & $\begin{array}{c}\text { 3 wt.\% of } \\
\text { Garnet }\end{array}$ & $\begin{array}{r}\text { 6 wt.\% of } \\
\text { Garnet }\end{array}$ & $\begin{array}{c}\text { 9 wt.\% of } \\
\text { Garnet }\end{array}$ & $\begin{array}{c}\text { 12 wt.\% } \\
\text { of Garnet }\end{array}$ \\
\hline 10 & 493 & 514 & 555 & 542 \\
20 & 498 & 518 & 575 & 560 \\
25 & 520 & 553 & 635 & 598 \\
No chill & 490 & 499 & 542 & 530 \\
\hline
\end{tabular}

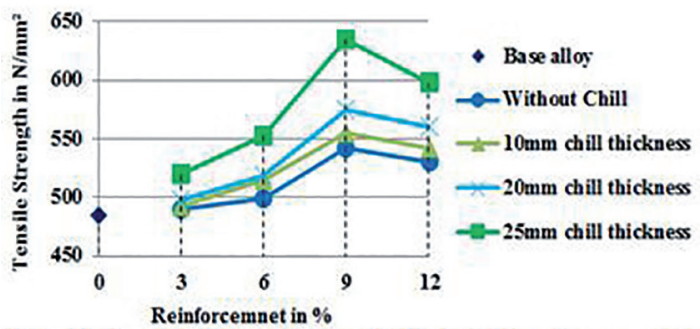

Figure 8: Tensile strength of Nickel based composite with varying chill thickness and \% Garnet reinforcement. 


\subsection{Hardness Test}

Table 6: BHN [Brinell hardness] of cryo-chilled reinforced metal matrix cast using copper chills of varying thickness.

\begin{tabular}{lcccc}
\hline $\begin{array}{l}\text { Chill } \\
\text { thickness } \\
\text { in mm }\end{array}$ & $\begin{array}{c}\text { 3 wt.\% of } \\
\text { Garnet }\end{array}$ & $\begin{array}{c}\text { 6 wt.\% of } \\
\text { Garnet }\end{array}$ & $\begin{array}{c}\text { 9 wt.\% of } \\
\text { Garnet }\end{array}$ & $\begin{array}{c}\text { 12 wt.\% } \\
\text { of Garnet }\end{array}$ \\
\hline 10 & 210 & 213 & 218 & 214 \\
20 & 212 & 216 & 220 & 218 \\
25 & 216 & 219 & 233 & 225 \\
No chill & 205 & 208 & 215 & 210 \\
\hline
\end{tabular}

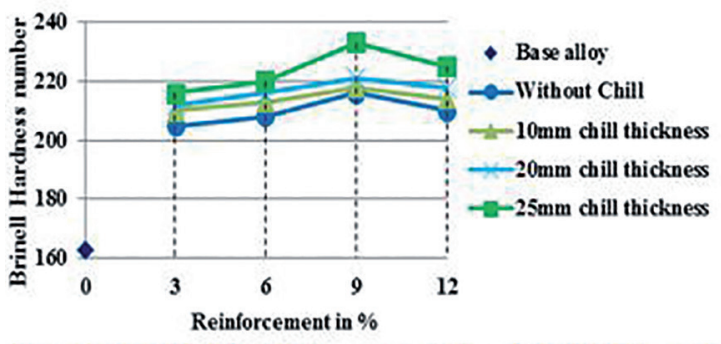

Figure 9: Brinell hardness number of Nickel based composite with varying chill thickness and \% Garnet reinforcement.

\subsection{Discussions}

It is observed from the optical micrographs shown in Figure 5. With reference to the base alloy microstructure, the matrix alloys are uniformly distributed in reinforced particles. This is due to the stirring action and density difference between matrix material and the reinforcement made the particles to segregate uniformly without allowing time to settle down. The cryogenic effect of passing liquid nitrogen through chills during solidification caused stronger bonding between the matrix material and the reinforcement with very limited clusters, matrix material interfacial integrity, and improved grain refinement with minimum porosity. Bonding is perfect between matrix and reinforcement due to preheating of the garnet particle. Micro porosity is also not observed in the microstructure due to cryogenic effect. Finally, microstructure reveals fine grain structure which is observed through scanning electron microscopy shown in Figure 6. And also Figure 7 shows the chemical compositions of developed nickel alloy and garnet reinforced particles analysed through EDS. Table 3 illustrate the EDS analysis data which strongly suggest that the compositions of ASTM A 494 M grade nickel alloy and varying 3 -12 wt. $\%$ garnet particles.

The tensile testing of the developed composite result in the Table 5 shows the ultimate tensile strength (UTS) measured by considering the specimen from the chill end for Nickel matrix/reinforced composites cast of different thickness. It is observed that the tensile strength of no chill cast composite are lower than that of the remaining chill cast composite with varying chill thickness. As the chill thickness increases, UTS also increases confirming that the volumetric heat capacity (VHC) of the copper chill along with liquid nitrogen significantly enhances the grain structure. As the reinforcement content is increased; the tensile strength is also increases. The increase in tensile strength is due to the presence and uniform distribution of garnet reinforcements which is having inferred high strength, and grain structure obtained from the cryogenic chilling. UTS of different cast composites with varying reinforcement weight percentage and chill thickness is shown in Figure 8. The result shows that tensile strength is increasing up to 9 wt. \% Garnet content and then start gradually decreasing for $12 \mathrm{wt} \%$, where the trend is reverse.

The result in the Table 6 shows the Brinell hardness (BHN) value obtained for varying chill thickness and Garnet content. Like UTS, BHN also increases as the chill thickness increases. This once again confirms that the VHC of the chill enhances not only the UTS but also the BHN. Compared with no chill cast composites the hardness value is higher in the cryogenic chill cast composite specimens. This significant increase in the hardness can be attributed primarily due to presence of harder garnet particulates in the matrix alloy with reference to the hardness of the matrix alloy 163 BHN shown in Table 4. From the graph shown in Figure 9 the hardness values demonstrate the pattern that as the percentage of Garnet is increased from $3 \mathrm{wt}$. \% to $9 \mathrm{wt}$. $\%$ there is an increase in the composite's hardness. Later there is a decrease in the hardness when garnet substance is extended to $12 \mathrm{wt}$. $\%$.

\section{Conclusion}

(1) ASTM A 494 M grade Nickel matrix alloy and garnet reinforced composites were successfully cast by stir casting route using varying thickness of cryogenically cooled copper chill material. From the analysis of the cast specimens the following conclusions can be revealed.

(2) Microstructural analysis using optical micrograph and SEM showed the grain refinement, fairly uniform distribution of the added Garnet particulates with minimum porosities.

(3)Uniform distribution of added Garnet particles and good bonding with the matrix alloy is obtained because of the stirring action.

(4)Fine grain structure and soundness of the composite is dependent on cryo chilling effect.

(5) Mechanical property characterization of composite cast using $10 \mathrm{~mm}, 15 \mathrm{~mm}$ and $25 \mathrm{~mm}$ thick copper chill block containing 3 to $12 \mathrm{wt} . \%$ reinforcement revealed that the presence of garnet particulates in nickel matrix has significantly improved hardness by $14 \%$ and tensile strength by $13 \%$ (in case of $25 \mathrm{~mm}$ copper end chill thickness). 
(6) Compared to no chill cast composite there is significant increase in mechanical property of the cryo chilling cast composite specimen.

(7) It was found that mechanical properties can be improved with increase in Garnet particles content up to 9 wt. \%, beyond which at $12 \mathrm{wt} . \%$ the trend reverses.

(8) It is clearly indicated by EDS test that the Garnet content is distributed in right proportion in the matrix alloy.

(9) Finally, the test result showed that these MMCs were greatly influenced by the Garnet particles addition and cryogenic effect. Hardness and UTS of the composite are found to depend on the wt. $\%$ of the dispersoid and thickness of chilling. Effect of heat capacity of cryogenic chill is highly dependent on the chilling rate and chill thickness.

\section{References}

1. Reed RC. The Superalloys - Fundamentals and Applications. Cambridge: Cambridge University Press; 2006.

2. Smith WF. Structure and properties of engineering alloys $-2^{\text {nd }}$ ed. New York: McGraw-Hill; 1993.

3. Erol A, Yonetken A, Yildiz I, Erdogan M. Fabrication of Ni MMC reinforced with $\mathrm{SiO}^{2}$ by microwave sintering. In: $5^{\text {th }}$ International Advanced Technologies Symposium; 2009 May 13-15; Karabük, Turkey.

4. Purshotham G, Hemanth J. Effect of Chilling on Soundness, Micro Hardness and Ultimate Tensile Strength of Nickel Alloy-Fused Silica Metal Matrix Composite. International Journal of Civil, Mechanical and Energy Science. 2016;2(1):25-28.

5. Ren Z, Meng N, Shehzad K, Xu Y, Qu S, Yu B, et al. Mechanical properties of nickel-graphene composites synthesized by electrochemical deposition. Nanotechnology. 2015;26(6):065706.

6. Zhang L, Shi N, Gong J, Sun C. Preparation of SiC Fiber Reinforced Nickel Matrix Composite. Journal of Materials Science \& Technology. 2012;28(3):234-240.

7. Novák P, Šotka D, Novák M, Michalcová A, ŠerákJ, Vojtěch D. Preparation of NiAl-ceramics composite by reactive sintering. In: METAL-2010; 2010 May 18-20; Rožnov pod Radhoštěm, Czech Republic. p. 231-236.

8. Lu J, Yang S, Wang J, Xue Q. Mechanical and tribological properties of Ni-based alloy/ $\mathrm{CeF}_{3} /$ graphite high temperature self-lubricating composites. Wear. 2001;249(12):1070-1076.

9. Cai B, Tan YF, Tu YQ, Wang XL, Tan H. Tribological properties of Ni-base alloy composite coating modified by both graphite and TiC particles. Transactions of Nonferrous Metals Society of China. 2011;21(11):2426-2432.

10. Srivastava M, Srinivasan A, Grips VKW. Influence of zirconia incorporation on the mechanical and chemical properties of Ni-Co alloys. American Journal of Material Science. 2011;1(2):113-122.

11. Chawla K. K, Composite Materials - Science and Engineering, 2nd Ed., Springer-Verlag, New York, 1997, 102.
12. Yogeska KB, Hemanth J. Mechanical properties of metallic \& non-metallic chilled austempered ductile iron (ACDI) International Journal of Advanced Engineering Research and Studies. 2012;1(2):240-243.

13. Hemanth J. Action of chills on soundness and ultimate tensile strength (UTS) of aluminum-quartz particulate composite. Journal of Alloys and Compounds. 2000;296(1-2):193-200.

14. Li G, Huang J, Wu Y. An investigation on microstructure and properties of dissimilar welded Inconel 625 and SUS 304 using high-power $\mathrm{CO} 2$ laser. The International Journal of Advanced Manufacturing Technology. 2015;76(5):1203-1214.

15. Liyanage T, Fisher G, Gerlich AP. Microstructures and abrasive wear performance of PTAW deposited Ni-WC overlays using different Ni-alloy chemistries. Wear. 2012;274-275:345-354.

16. Xu FJ, Lv YH, Liu YX, Shu FG, He P, Xu BS. Microstructural evolution and mechanical properties of Inconel 625 alloy during pulsed plasma arc deposition process. Journal of Material Science and Technology. 2013;29(5):480-488.

17. Gurumoorthy K, Kamaraj M, Rao KP, Venugopal S. Microstructure and wear characteristics of nickel based hardfacing alloys deposited by plasma transferred arc welding. Materials Science and Technology. 2006;22(8):975-980.

18. Hemanth J. Cryo effect during solidification on the tribological of aluminium-alloy/glass $\left(\mathrm{SiO}_{2}\right)$ metal matrix composites. Journal of Composite Materials. 2009;43(6):675-688.

19. Jaya Prakash RH, Budan A, Hemanth J. Fabrication and mechanical properties (strength \& hardness) of cryogenically solidified nano metal matrix composites (CNMMC's). International Journal of Emerging Technology and Advanced Engineering. 2014;4(7):378-382.

20. Seah KHW, Krishna M, Vijayalakshmi VT, Uchil J. Corrosion behaviour of garnet particulate reinforced LM13 Al alloy MMCs. Corrosion Science. 2002;44(5):917-925.

21. Anantha Prasad MG, Bandekar N. Study of Microstructure and Mechanical Behaviour of Aluminum /Garnet/Carbon Hybrid Metal Matrix Composites (HMMCs) Fabricated by Chill Casting Method. Journal of Materials Science and Chemical Engineering. 2015;3(3):1-8.

22. American Society for Testing and Materials - ASTM E3-11, Standard Guide for Preparation of Metallographic Specimens, ASTM International, West Conshohocken, PA, 2011, www. astm.org

23. American Society for Testing and Materials - ASTM E8 / E8M15a, Standard Test Methods for Tension Testing of Metallic Materials, ASTM International, West Conshohocken, PA, 2015, www.astm.org.

24. American Society for Testing and Materials - ASTM E1015a, Standard Test Method for Brinell Hardness of Metallic Materials, ASTM International, West Conshohocken, PA, 2015, www.astm.org 